\title{
The P2 Receptors and Congenital Platelet Function Defects
}

\section{Marco Cattaneo, M.D.}

In the above-mentioned article, published in Seminars in Thrombosis and Hemostasis 2005; Volume 31, Number 2, pages 168-173, page 170, paragraph 1, line 3 should read:

$\mathrm{P}_{12} \mathrm{Y}_{12}$ is the target of efficacious antithrombotic agents like ticlopidine and clopidogrel, ${ }^{2,32}$ which are already used in clinical practice, and the AR-C compounds, ${ }^{33}$ one of which is currently under evaluation in clinical trials.

Tissue Factor; Editor in Chief, Eberhard F. Mammen, M.D.; Guest Editor, Marcel Levi, M.D., Ph.D. Seminars in Thrombosis and Hemostasis, volume 32, number 1, 2006. Address for correspondence and reprint requests: Professor Marco Cattaneo, Unit of Hematology and Thrombosis, Ospedale San Paolo, DMCO University of Milan, Via di Rudinì, 8, 20142 Milan, Italy. E-mail: marco.cattaneo@unimi.it. Copyright (C) 2006 by Thieme Medical Publishers, Inc., 333 Seventh Avenue, New York, NY 10001, USA. Tel: +1(212) 584-4662. 0094-6176,p;2006,32,01,077,078, $\mathrm{ftx}$,en;sth01133x. 
